\title{
EDITORIAL
}

\section{THE ECONOMETRICS OF INDUSTRIAL ORGANIZATION}

This Special Issue of the Journal of Applied Econometrics contains a selection of papers presented at the 15th (EC) ${ }^{2}$ conference on 'The Econometrics of Industrial Organization' held in Marseille, France, from 16 to 18 December 2004.

$(E C)^{2}$ stands for European Conference of the Econom(etr)ics Community. The (EC) $)^{2}$ conference series was established in 1990. The meetings are small-scale conferences, organized around a particular theme, and take place over 2 days.

The main purpose of $(\mathrm{EC})^{2}$ conferences is to provide a forum where European researchers in quantitative economics and econometrics can meet to discuss the results and progress of their most recent research. In particular, the intention of the $(\mathrm{EC})^{2}$ conferences is to promote and foster interaction between the junior participants and the senior invited researchers. The Programme Chair for this meeting was Alvaro Escribano, with Michel Lubrano acting as Local Organizer.

The theme of this conference and this Special Issue is 'The Econometrics of Industrial Organization' (IO). The novelty of the 2004 meeting was to bring together people doing applied IO with econometricians. This led to exchanges on these fundamental issues from leading researchers working in the fiel of micro-econometrics and on empirical aspects of competition issues in different markets (retail, automobile, electricity, advertising, newspapers, transport, etc.) and broad issues like eff ciency measures or the analysis of $R \& D$ decisions of firms The range of topics covered by the papers presented in both the plenary and poster sessions reflecte this breadth.

It is important to emphasize that this Special Issue is by no means a proceedings volume. Many more papers were presented during the conference than those that were accepted for publication after a reviewing process. The Editors firs of all chose papers on the basis of the importance of their contribution and the proximity to the theme of the conference. The papers that are collected here have all undergone a rigorous reviewing and revision process. Note that the ordering of the papers in this Special Issue is made so as to ref ect these groupings and their intersection as far as possible.

The frst paper, by Jerry Hausman and Ephraim Leibtag, analyses the welfare impact of new retail outlets using a framework developed to analyse the introduction of new goods in a differentiated market (the spread of non-traditional retail outlets). Non-traditional retail outlets, including supercentres (like Wal-Mart), warehouse club stores and mass merchandisers, have recently grown in popularity. Consumers gain directly from the availability of new outlets ('new goods') as they provide more choice in a geographic market and, in the studied scenario, also lower prices. There are additional, indirect gains because competition increases and existing outlets respond by lowering their prices. The direct effect is estimated to be very large, approximately $20 \%$ compensating variation, and the indirect effect is an additional $5 \%$. As it turns out, the effect shows up and the welfare effects are even larger than one would probably have expected. Compensating variation estimates are lower when households have a random willingness to pay for quality, but the reduction is only minor. The authors $\mathrm{f}$ nd that lower-income households tend to shop more at these low-priced outlets and their compensating variation from supercentres is higher than for higher-income households. 
Frank Wolak brings a number of useful insights into the electricity literature such as the importance of ramping costs and the quantificatio of the impact of forward contracts on the effective marginal costs the frms face. Under the null hypothesis of expected profit-maximizin bidding behaviour in a multi-unit, multi-period auction with step-function supply curves he estimates cost functions for electricity generation units and derives tests of expected profit maximizing behaviour by testing the over-identifying moment restrictions. These cost function estimates quantify the output-varying costs and how forward contracts impact the electricity generation costs that the owner incurs. This estimation procedure relies on the assumption of best-reply behaviour on the part of an individual market participant, and it is unnecessary to solve for the market equilibrium to apply this procedure. Therefore, this methodology could have wide empirical applications since it could be applied to multi-unit auctions that use step-function bid curves like, for example, treasury bills, spectrum and multiple items on eBay.

Jean-Thomas Bernard, Nadhem Idoudi, Lynda Khalaf and Clément Yélou estimate dynamic energy demand equations on Quebec data. Key parameters of interest are long-run price and income elasticities. The Delta method is commonly used to provide confidenc intervals because long-run elasticities are nonlinear transformations of original parameters. However, Dufour and Kiviet (1998) have shown that this leads to inconsistent results. Because Dufour and Kiviet's (1998) alternative method is costly, the authors investigate the performance of an alternative method based on Fieller's theorem. A small Monte Carlo experiment shows the inadequacy of the Delta method when approaching the unit root as opposed to the stability of Fieller's method. Their sample covers two oil crises and a price deregulation. Demand equations appear to be stable for large industries and unstable for small ones. Finally, price elasticities less than minus one are not part of Fieller's confidenc sets, revealing that energy demand can be said to be price inelastic in Quebec.

Joris Pinkse and Margaret Slade develop a dynamic discrete-choice methodology for estimating policy functions of dynamic games which include the choice of discrete and continuous controls. As an application, they estimate the rules of choice for performing advertising in a dynamic game of price and advertising. The estimation is carried out with data on the weekly sales of a similar product by three food brands in 10 stores over 2 years. The paper concludes that advertising expands the market but that the effect on consumer welfare is ambiguous since there is also an increase in prices (pay for the better information). They evaluate the long-run effects of promotional decisions in an industry that produces an established standardized product. The non-structural approach allows the authors to make some interesting judgments while avoiding most of the computational burden associated with the structural estimation of dynamic games. Their methodology is especially useful when there are many choices and when choices can be correlated across decision makers (for example, if $\mathrm{frms}$ behave in a strategic manner).

Argentesi and Filistrucchi deal with the estimation of market power in the Italian national newspaper market. This is a market with two sides: one consisting of readers and the other of advertisers. The interaction between the two sides is obvious; in particular, an increased audience should attract more advertising. Newspapers maximize profit by taking account of the interaction. They can either compete or collude on each side of the market (leading to four possible market structures). The authors estimate a demand equation for each side, which takes account of the impact of audience on advertising demand. They use the estimates to compute the mark-ups implied by the different market structures and fin that the mark-up estimated from accounting data is best matched by the mark-up implied by the structure wherein newspapers compete (through prices) for advertising and collude to fi the newspaper cover price. 
The paper by J. Luis Guasch, Jean-Jacques Laffont and Stéphane Straub extends the theoretical model of Guasch, Laffont and Straub (2003), adding new features such as considering a twoperiod scenario, which allows the introduction of political elections between both periods, so that there is a positive probability of a change of government. Political cycles were found to have an impact on the renegotiation of concessions; therefore they have extended their previous model to propose a more convincing interpretation of their findin that elections have a strong influenc on renegotiation. The empirical section of the paper tests the main hypothesis derived from the model. A probability model is estimated to analyse the impact of different variables on the probability of government-led renegotiation of concessions, controlling for the endogeneity of the regressors. The database used in the estimation is formed by 307 concessions in transport and water industries from Argentina, Brazil, Chile, Colombia and Mexico. The authors analyse the main variables having an influenc on renegotiations initiated by $\mathrm{frms}$, concentrating in this paper on the main factors influencin government-led renegotiations. Most of the empirical results (like those based on the relevance of an independent regulatory body, influenc of type of regulation, impact of change of government after elections, degree of corruption and weakness in the rule of law), are as expected, while some others regarding f nancing variables are also interesting but less predictable.

Michel Mouchart and Marie Vandresse deal with the detection of market imperfections and the estimation of bargaining power in the market of freight transport. A freight contract is made of a vector of prices and a vector of attributes (speed, f exibility and reliability). Data are collected by interviewing Belgian freight companies. A non-parametric analysis of the sample leads to the definitio of upper and lower frontiers which are identifie to bid demand and bid supply functions, respectively. The distance between these two functions measures the range of prices that are paid for a given set of attributes and corresponds to market imperfection. A measure of bargaining power for each contract follows. The market appears to be dominated by the demand side and to have large imperfections. However, their sample is very small, with 90 observations, and covers only $20 \%$ of the profession. In this context, Mouchart and Vandresse adapt the bootstrap testing procedure of Simar and Wilson (2001) to test whether a particular attribute could have a dominant effect or if the market could be segmented between road and rail. The answer is no. However, another segmentation appears to have a dramatic effect on the results: retail and dangerous goods.

Johannes Van Biesebroeck's paper highlights that the number of car and light truck models in North America has increased quite dramatically over the last decade. To a large extent, this increase in variety has been driven by consumers. Producing a larger number of different cars, and/or variations of a model, lowers average productivity. The author explores whether adopting complementary activities, such as insourcing (previous activities that where outsourced) and introducing f exible technology (ability to assemble models derived from different 'platforms' on the same assembly line), allows car assemblers to reduce this productivity penalty. This paper explores how established manufacturers in a capital-intensive, highly unionized industry, can successfully adapt to changing and increasingly volatile consumer tastes. The complementarities found in a framework that studies the joint impact on the performance variable is robust to controlling for the endogeneity of the adoption decisions using activity-specifi instruments.

Aware of the increasing gap in research investment between the European Union and the United States, the European Council Member States decided to promote investment in Research and Development (R\&D) so as to reach the objective of 3\% of GDP at the horizon of 2010. Dirk Czarnitzki, Bernd Ebersberger and Andreas Fier analyse the efficienc of a public funding policy aimed at promoting R\&D collaboration between firm in Finland and in Germany. Because of 
spillovers, collaboration should increase R\&D investment. A selection bias is due to the fact that the group of public funded companies is different from the group of companies not receiving public funding. They use a matching technique due to Lechner (2001) (among others) to remove the selection bias. They conclude that the combination of collaboration and subsidies improves R\&D spending and patent activity. But funding alone has no significan effect.

Data envelopment analysis (DEA) is widely used to determine production frontiers and then measure the efficienc of each fir for a given industry. Léopold Simar and Valentin Zelenyuk start from Farrell-type efficienc measures for each fir and then look for an aggregate index for the whole industry. They provide an existence theorem for optimal aggregation and weight determination. Asymptotic results have recently been found for DEA estimators. Simar and Zelenyuk propose a consistent bootstrap algorithm for the group-wise heterogeneous case. They obtain bootstrap estimates of the aggregate eff ciency scores from which they derive bootstrap confidenc intervals, bias corrected estimates and standard errors for the industry eff ciency index. They provide an extended empirical application over 152 firm of the industrial sector of Ukraine.

Luc Bauwens CORE and Department of Economics Université catholique de Louvain Belgium

\author{
Alvaro Escribano \\ Department of Economics \\ Universidad Carlos III de Madrid \\ Spain
}

Michel Lubrano Centre de la Vieille Charité GREQAM-CNRS Marseille

France 